Research Article

\title{
Maspin, Syndecan-1, and Ki-67 in the Odontogenic Keratocyst: An Immunohistochemical Analysis
}

\author{
Huda M. Hammad (D), ${ }^{1}$ Omar M. Nagrash, ${ }^{2}$ and Rima A. Safadi ${ }^{1}$ \\ ${ }^{1}$ Department of Oral Medicine and Oral Surgery, Faculty of Dentistry, Jordan University of Science and Technology, \\ P. O. Box 3030, Irbid 22110, Jordan \\ ${ }^{2}$ Al-Ramtha Governmental Hospital, Ministry of Health, P. O. Box 132, Al-Ramtha 21410, Jordan \\ Correspondence should be addressed to Huda M. Hammad; hmhammad@just.edu.jo
}

Received 27 November 2019; Revised 27 May 2020; Accepted 16 June 2020; Published 14 July 2020

Academic Editor: Leonzio Fortunato

Copyright (c) 2020 Huda M. Hammad et al. This is an open access article distributed under the Creative Commons Attribution License, which permits unrestricted use, distribution, and reproduction in any medium, provided the original work is properly cited.

\begin{abstract}
The odontogenic keratocyst (OKC) is a controversial lesion that was reclassified as a tumor with the name "keratocystic odontogenic tumor" in 2005. The reclassification was revoked recently in 2017, with a conclusion on the need for further studies on the subject. In this study, the expressions of an important regulatory protein (maspin), an important integral membrane proteoglycan (syndecan-1), and a universal proliferation marker (Ki-67) in the epithelium of the OKC were investigated in comparison with the dentigerous cyst (DC) and ameloblastoma (AB). Twenty-six OKCs, eleven DCs, and ten conventional ABs were immunohistochemically stained for maspin, syndecan-1, and Ki-67. ImageJ was used to analyze the positivity of maspin and syndecan-1. The Ki-67 score was calculated as the percentage of positive nuclei in 5 high power fields. Analysis of variance (ANOVA) test and Student $t$-test were used as appropriate. Lower expressions of maspin were noted in $\mathrm{OKC}$ and $\mathrm{DC}$ compared to those in $\mathrm{AB}$, and lower expressions of syndecan-1 were noted in $\mathrm{OKC}$ and $\mathrm{AB}$ compared to those in DC. The differences, however, did not reach statistical significance (ANOVA and $t$-test: $P>0.05$ ). The Ki-67 score was significantly higher in $\mathrm{OKC}$ than in DC $(t$-test: $P<0.05)$, and not significantly different from AB $(t$-test: $P>0.05)$. In conclusion, expressions of maspin and syndecan-1 are not strongly representative of differences in behavior between OKC, $\mathrm{AB}$, and DC. However, the expression of Ki-67 indicates comparable proliferative activities of OKC and AB, which are higher than that of DC. Further investigation on the biologic behavior of OKC is still recommended to arrive at more specific conclusions regarding its classification.
\end{abstract}

\section{Introduction}

Odontogenic keratocysts (OKCs) comprise a significant proportion of odontogenic cysts. They are known to show locally aggressive behavior with a tendency to recur following excision. OKCs occur in both jaws, with a predilection to affect the posterior body, angle, and ramus area of the mandible. OKCs may occur as solitary or multiple lesions, and multiple OKCs may be associated with the nevoid basal cell carcinoma syndrome [1].

The OKC was reclassified as a tumor with the name "keratocystic odontogenic tumor" in 2005 [2]. Despite the accumulation of research work supporting this reclassification, the debate on whether to consider it as a tumor or cyst did not stop [1]. Moreover, the term "OKC" continued to be used by the scientific community more favorably than "keratocystic odontogenic tumor" [3]. The debate has culminated recently in the revocation of the reclassification in the 2017 WHO classification of diseases [4].

Various immunohistochemical studies have been conducted to investigate the biologic nature of OKCs, such as those assessing proliferation markers (Ki-67 and PCNA) [5-19] and the tumor suppressor gene P53 and other members of the P53 family [8, 12, 14, 15, 17, 18, 20-25]. Higher proliferative activity and more significant or different P53 expression in the OKC compared to other odontogenic cysts have been reported [5-9, 12-14, 16-22, 24]. Additionally, mutations or abnormalities of the PTCH, P53, P16, 
and MCC tumor suppressor genes have been reported to be associated with the etiology of sporadic and syndromic OKCs [26-33].

Despite the higher proliferative activity in the OKC than in other odontogenic cysts [5-9, 12-14, 16-19], the clinical regression of some OKCs following marsupialization is known to occur [34]. This fact was among the causes for revocation of the 2005 classification, since regression is not a feature of neoplasia $[35,36]$, and therefore, more investigations of the biologic nature of OKCs were recommended.

Some biologic markers have not been investigated in the OKC yet, such as mammary serine protease inhibitor (maspin). Other markers were investigated only in a few studies, such as syndecan-1 [37-41].

Maspin can be detected in many normal tissues, mainly epithelial. It has been determined to function as a tumor suppressor by increasing cell adhesion and apoptosis and decreasing motility, angiogenesis, and pericellular proteolysis [42]. Its expression may be either down- or upregulated in several benign and malignant tumors, and thus, its expression is considered to have prognostic implications. Its therapeutic effects are also being investigated [43].

Syndecan-1, also known as CD138, is a member of the syndecan family, which are integral membrane heparan sulfate proteoglycans. It is essential in cell-cell and cellmatrix interactions [44, 45]. It is mainly expressed in epithelial cells and plasmacytes. Its immunoexpression is altered in many inflammatory, infectious, fibrotic, and neoplastic diseases. Certain molecular pathways in which syndecan-1 is involved are deregulated during carcinogenesis. These pathways are related to cell proliferation, angiogenesis, apoptosis, and tumor invasion [45]. The altered immunoexpression in various types of cancer is sometimes correlated with patients' prognosis and clinicopathologic parameters $[44,45]$. Due to its important role in carcinogenesis, syndecan-1 is a promising target for anticancer therapy [45].

This study aimed to continue the investigation of the biological nature of the OKC and shed more light on the "tumorous" versus "cystic" nature of this lesion. The expression and distribution of maspin and syndecan-1 were immunohistochemically investigated in the OKC and compared to those in the dentigerous cyst (DC) and ameloblastoma (AB). The expression of $\mathrm{Ki}-67$ was also studied to be used as a baseline reference since its expression is already established in the literature $[5,7,8,11-13,15-19]$.

\section{Materials and Methods}

All necessary approvals were obtained from the Deanship of Research, Jordan University of Science and Technology, including the Institutional Review Board approval.

2.1. Tissue Samples. The archives of the biopsy service of the Department of Pathology and Microbiology, Faculty of Medicine, Jordan University of Science and Technology, and the Pathology Laboratory at the King Abdullah University Hospital were reviewed for biopsies diagnosed as OKC, DC, and $\mathrm{AB}$ during twenty years. Inclusion criteria for $\mathrm{OKC}$ and DC were minimal or no inflammation and well-oriented tissue sections. For AB, inclusion criteria were conventional type and well-oriented tissue sections. An experienced oral pathologist evaluated the retrieved sections, and 26 OKCs, 11 DCs, and $10 \mathrm{ABs}$ were included in the study.

2.2. Immunohistochemical Procedure. Three $4 \mu \mathrm{m}$ thick sections were cut from each tissue block and mounted on positively charged glass microscopic slides (Superfrost Plus microscope slides, 060SFP, DiaPath, Martinengo, Italy) coated with VECTABOND ${ }^{\mathrm{TM}}$ Reagent (SP-1800, Vector Laboratories, Inc., Burlingame, CA, USA). The three sections were used for immunohistochemical staining for maspin, syndecan-1, and Ki-67. An additional section was cut from each specimen for routine $\mathrm{H} \& \mathrm{E}$ staining. More sections were cut from one of the OKC specimens to be used as a negative control in each immunohistochemical run.

The immunohistochemical staining was performed using an automatic stainer (Dako Autostainer Plus, DakoCytomation Denmark, Glostrup, Denmark). The standard procedure using the EnVision ${ }^{\mathrm{TM}}+$ Dual Link System-HRP, Code K4061 (Dako, Glostrup, Denmark) was used, followed by Liquid DAB + substrate-chromogen system, code K3468 (Dako, Glostrup, Denmark). Sections were then counterstained with Mayer's hematoxylin.

The primary antibodies used were: rabbit anti-maspin polyclonal antibody, Maspin H-130: sc-22762, dilution 1 : 150 (Santa Cruz Biotechnology, Inc., Santa Cruz, California, USA), monoclonal mouse anti-human CD138, clone MI15, code M 7228, dilution 1:100 (Dako, Glostrup, Denmark), and monoclonal mouse anti-human Ki-67 antigen, clone MIB-1, code IS626, ready to use (Dako, Glostrup, Denmark).

In negative control sections for each run, the primary antibody was replaced by nonspecific mouse immunoglobulin $G$ at 1:150 dilution (Biogenex Laboratories Inc., San Ramon, CA, USA). Occasional plasma cells found in some sections in each run served as internal positive controls for syndecan-1. Normal breast tissue was used as a positive control for maspin, and a case or oral squamous cell carcinoma was used as a positive control for Ki-67.

2.3. Microscopic Evaluation and Imaging. Digital images of two fields at $\times 400$ magnification were acquired from each section stained with maspin or syndecan-1, using an Olympus DP20-5 digital camera mounted on an Olympus BX50 light microscope (Olympus Corporation, Tokyo, Japan). The most representative field was selected for image analysis. For Ki-67 stained sections, images of five high power fields (HPFs) at $\times 400$ magnification were acquired to allow calculation of the Ki-67 score.

2.4. Image Analysis. Digital images of tissue sections stained for maspin and syndecan-1 were prepared for analysis using the ImageJ 1.44 program. ImageJ is a public domain Java image processing program developed at the National Institute of Health (Bethesda, Maryland, USA). The Color 
Deconvolution Plug-in was downloaded into the ImageJ program and used to isolate positively stained areas from the total epithelial area as previously described [46]. For Ki-67 stained sections, the percentage of Ki-67 positive cells in 5 $\mathrm{HPF}$ for each case was determined and expressed as the Ki67 score $[47,48]$.

2.5. Statistical Analysis. Data for each diagnostic group were entered into the Statistical Package for the Social Sciences (SPSS) version 15 (SPSS Inc., Chicago, IL, USA). The percentage of the positive area was calculated by dividing the positive area by the total epithelial area for each case. The mean proportions between the different groups in the study were compared using parametric tests. The significance of immunohistochemical positivity as a factor in separating the diagnostic groups was calculated using the ANOVA test. Pairwise comparisons were performed using the Student $t$ test. The significant $P$-value was considered to be less than 0.05 .

\section{Results}

3.1. Microscopic Findings. Negative and positive control sections included in each run were evaluated before analyzing the study tissue sections. All negative control sections consistently showed a lack of brown staining. Breast tissue used as a positive control for maspin showed strong expression in myoepithelial cells and weaker focal expression in glandular epithelial cells. Occasional plasma cells used as an internal positive control for syndecan-1 showed strong membranous expression. Squamous cell carcinoma control tissue for Ki-67 showed nuclear staining of scattered cells.

All the OKCs were positive for maspin. The pattern of expression in the epithelium was both nuclear and cytoplasmic. The distribution involved the full epithelial thickness (Figure 1(a)). The expression of maspin in the epithelial lining of DCs was also cytoplasmic and nuclear. The distribution of maspin-positive cells involved the entire thickness of the epithelium (Figure 1(b)). All cells in AB sections showed positivity, but the peripheral columnar or cuboidal cells showed a stronger reaction than the stellate reticulum-like cells (Figure $1(\mathrm{c})$ ).

The expression of syndecan-1 in OKCs was localized to the membranes of epithelial cells and intercellular junctions in the entire thickness of the epithelium. The parakeratinized layer showed negative staining (Figure 2(a)). Similarly, syndecan-1 expression in DCs was localized to the cell membranes of epithelial cells (Figure 2(b)). All cases of AB showed positive immunoreactions with syndecan-1. Stellate reticulum-like cells reacted with stronger intensity than the peripheral columnar or cuboidal cells (Figure 2(c)). When present, areas of squamous metaplasia were not reactive.

The expression of Ki-67 protein in OKCs was exclusively localized to the nuclei of the basal and suprabasal cell layers of the epithelium. Nuclear expression was predominantly suprabasal, but occasional positive basal nuclei were present (Figure 3(a)). Occasional Ki-67 positive nuclei in DCs were primarily distributed in the basal cell layer (Figure 3(b)). All cases of $A B$ showed positive nuclear staining with Ki-67. Positive nuclei were predominant in the peripheral columnar and cuboidal cells, but stellate reticulum-like cells occasionally expressed Ki-67 positive nuclei (Figure 3(c)).

3.2. Image Analysis. Table 1 shows the frequency distribution of the mean, standard deviation, minimum, and maximum values of the percentages of maspin and syndecan-1 positive areas, and the Ki-67 scores in the three diagnostic groups. The mean percentages of maspin-positive areas were close for the $\mathrm{DC}$ and $\mathrm{OKC}$. The mean percentage for $\mathrm{AB}$ was the highest. The mean percentage of syndecan-1 positive areas had close values for the three groups. The mean $\mathrm{Ki}-67$ scores were close for the $\mathrm{OKC}$ and the $\mathrm{AB}$, and much lower for the DC.

Table 2 shows the results of multiple comparisons of the mean percentages of maspin and syndecan- 1 positive areas, and the Ki-67 score in the three diagnostic groups. The mean percentages of both maspin and syndecan-1 positive areas in the three diagnostic groups were not significantly different (ANOVA:P-value > 0.05). Meanwhile, the Ki-67 scores were significantly different (ANOVA: $P$-value $<0.05$ ) between the three groups.

Table 3 shows the results of paired comparisons of the mean percentages of maspin and syndecan-1 positive areas, and the Ki-67 scores in the OKC with that in the DC and $\mathrm{AB}$. The mean percentages of both maspin and syndecan-1 positive areas in the OKC were not significantly different from those in the DC nor the AB (independent samples $t$ test: $P$-value $>0.05)$. The mean Ki-67 score in the $\mathrm{OKC}$ was significantly higher than that in the DC (independent samples $t$-test: $P$-value $<0.05)$ and not significantly different from that in the $\mathrm{AB}$ (independent samples $t$-test: $P$-value $>0.05)$.

\section{Discussion}

The WHO reclassification of the OKC in 2005 as a benign odontogenic tumor rather than an odontogenic cyst was a result of its locally aggressive behavior and relatively high recurrence rate, in addition to the studies on genetic and molecular mechanisms involved in its development and progression [5-11, 20-22, 26-31]. The debate has culminated recently in the revocation of the reclassification in the 2017 WHO classification of diseases [4]. The consensus panel considered evidence of a neoplastic nature of OKC to be currently lacking or insufficient and concluded that further research on the subject is needed $[35,36]$.

In this study, maspin was investigated for the first time in the OKC to shed more light on the biologic aspect and add to the immunohistochemical profile of this "controversial" lesion. Maspin was found to be expressed in the entire epithelial thickness of all cases of OKC. The expression was similar in pattern among all study groups. The distribution was both cytoplasmic and nuclear, which is consistent with the pattern reported by Vered et al. [49]. In their study, they compared maspin expression in central low-grade mucoepidermoid carcinoma and glandular odontogenic cyst. They 

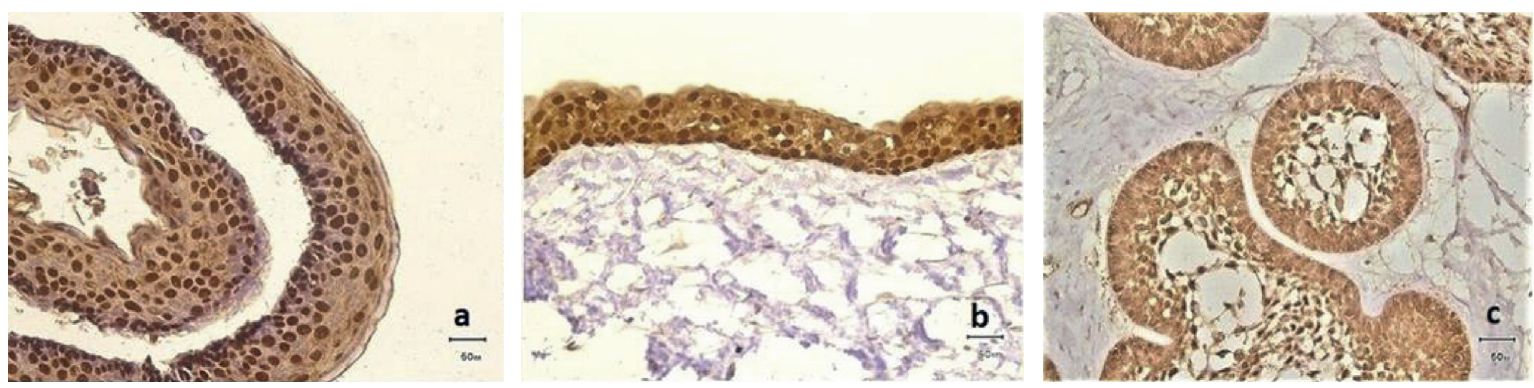

FIgURE 1: Immunohistochemical expression of maspin (a) in OKC epithelial lining, (b) in DC epithelial lining, and (c) in AB (original magnification $\times 400)$.
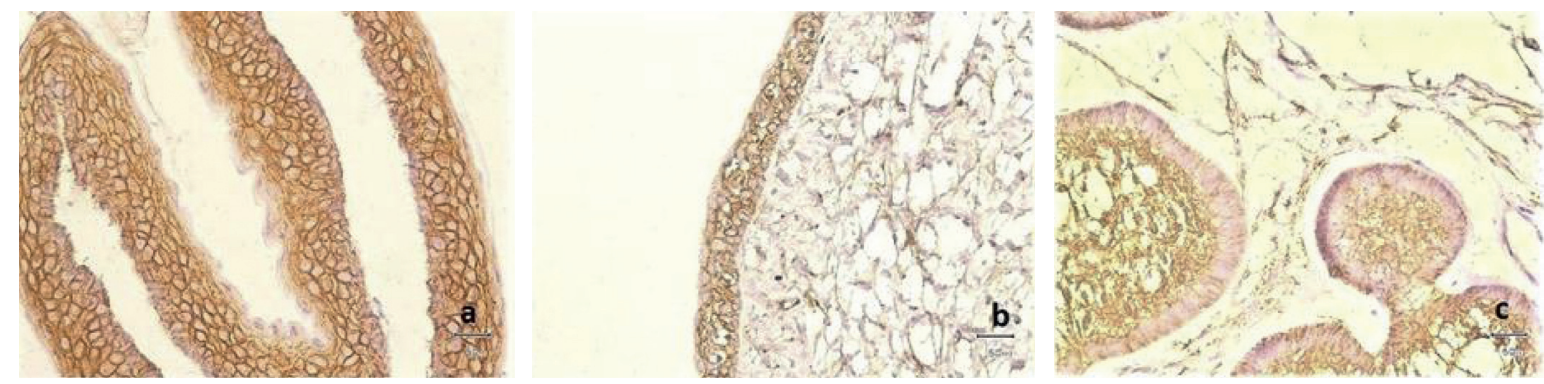

FIGURE 2: Immunohistochemical expression of syndecan-1 (a) in OKC epithelial lining, (b) in DC epithelial lining, and (c) in AB (original magnification $\times 400$ ).
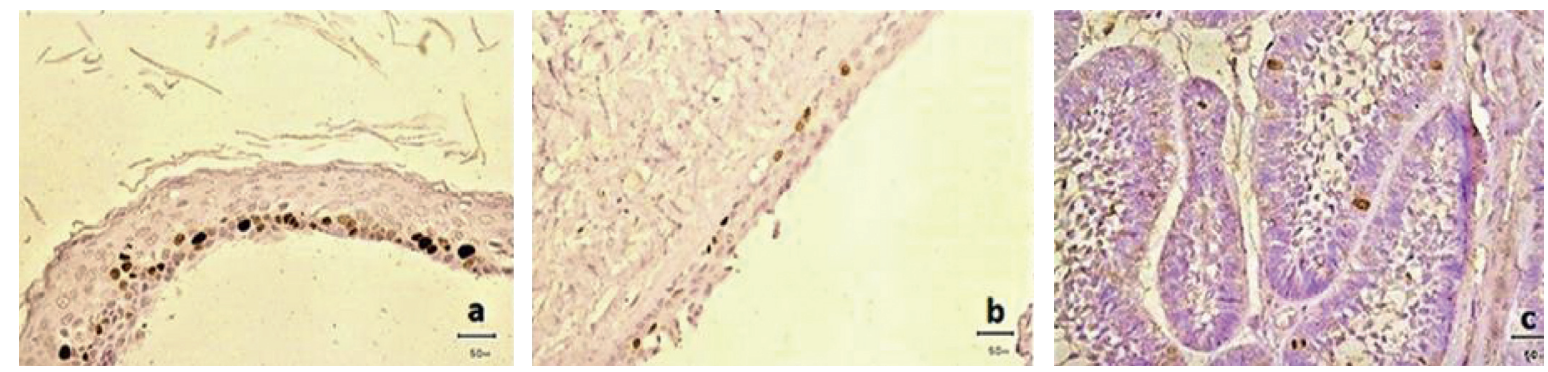

FIgURE 3: Immunohistochemical expression of Ki-67 (a) in OKC epithelial lining, (b) in DC epithelial lining, and (c) in AB (original magnification $\times 400)$.

TABle 1: Frequency distribution of the mean, standard deviation (SD), minimum, and maximum values of the percentages of maspinpositive areas, syndecan-1 positive areas, and the Ki-67 scores in the three study groups.

\begin{tabular}{|c|c|c|c|c|c|c|}
\hline Study group & Marker & $N^{*}$ & Mean positive area percentage & SD & Minimum percentage & Maximum percentage \\
\hline $\mathrm{OKC}$ & & 26 & $52.54 \%$ & 0.108 & $33 \%$ & $69 \%$ \\
\hline DC & Maspin & 11 & $53.36 \%$ & 0.099 & $41 \%$ & $66 \%$ \\
\hline $\mathrm{AB}$ & & 10 & $60.40 \%$ & 0.163 & $35 \%$ & $81 \%$ \\
\hline OKC & & 26 & $39.58 \%$ & 0.13 & $12 \%$ & $63 \%$ \\
\hline DC & Syndecan-1 & 11 & $43.18 \%$ & 0.18 & $11 \%$ & $81 \%$ \\
\hline $\mathrm{AB}$ & & 10 & $39.80 \%$ & 0.15 & $12 \%$ & $63 \%$ \\
\hline OKC & & 26 & $23^{* *}$ & 11.17 & 8 & 49 \\
\hline DC & $\mathrm{Ki}-67$ & 11 & $5^{* *}$ & 3.10 & 0 & 10 \\
\hline $\mathrm{AB}$ & & 10 & $24^{* *}$ & 20.65 & 0 & 62 \\
\hline
\end{tabular}

${ }^{*}$ Number of specimens. ${ }^{* *}$ Mean Ki-67 score.

used radicular and dentigerous cyst in which the epithelial lining showed mucous metaplasia as a control group. Cyst lining in all the cysts in the study showed positive immunohistochemical staining for maspin. The pattern was diffuse in both cytoplasm and nuclei of epithelial cells, but not in mucous cells, which were negative. 
TABLE 2: Multiple comparisons of the mean percentages of maspin-positive areas, syndecan-1 positive areas, and the Ki-67 scores in the three diagnostic groups, using ANOVA test. A significant $P$-value is shown in bold font.

\begin{tabular}{lccrr}
\hline Study group & Marker & $N^{*}$ & Mean positive area percentage & $F$ \\
\hline OKC & & 26 & $52.54 \%$ & 1.62 \\
DC & Maspin & 11 & $53.36 \%$ & 0.21 \\
AB & & 10 & $60.40 \%$ & 0.68 \\
\hline OKC & & 26 & $39.58 \%$ & 0.385 \\
DC & Syndecan-1 & 11 & $43.18 \%$ & \\
AB & & 10 & $39.80 \%$ & 9.52 \\
OKC & & 26 & $23^{* *}$ & $\mathbf{0 . 0 0 0}$ \\
DC & Ki-67 & 11 & $5^{* *}$ & \\
AB & & 10 & $24^{* *}$ & \\
\hline
\end{tabular}

${ }^{*}$ Number of specimens. ${ }^{* *}$ Mean Ki-67 score.

TABLE 3: Paired comparisons of the mean percentages of maspin and syndecan-1 positive areas, and Ki- 67 scores in the OKC with that in the $\mathrm{DC}$ and $\mathrm{AB}$, using the independent samples $t$-test. A significant $P$-value is shown in bold font.

\begin{tabular}{|c|c|c|c|c|c|c|}
\hline Study group & Marker & $N^{*}$ & Mean positive area percentage & $T$ & Mean difference & $P$ \\
\hline $\begin{array}{l}\mathrm{OKC} \\
\mathrm{DC}\end{array}$ & Maspin & $\begin{array}{l}26 \\
11\end{array}$ & $\begin{array}{l}52.54 \% \\
53.36 \%\end{array}$ & -0.22 & -0.008 & 0.8 \\
\hline $\begin{array}{l}\mathrm{OKC} \\
\mathrm{DC}\end{array}$ & Syndecan-1 & $\begin{array}{l}26 \\
11\end{array}$ & $\begin{array}{l}39.58 \% \\
43.18 \%\end{array}$ & -0.88 & -0.046 & 0.4 \\
\hline $\begin{array}{l}\mathrm{OKC} \\
\mathrm{DC}\end{array}$ & $\mathrm{Ki}-67$ & $\begin{array}{l}26 \\
11 \\
\end{array}$ & $\begin{array}{c}23^{* *} \\
5^{* *}\end{array}$ & 5.4 & 18.7 & $<0.0001$ \\
\hline $\begin{array}{l}\mathrm{OKC} \\
\mathrm{AB}\end{array}$ & Maspin & $\begin{array}{l}26 \\
10 \\
\end{array}$ & $\begin{array}{l}52.54 \% \\
60.40 \% \\
\end{array}$ & -1.7 & -0.079 & 0.1 \\
\hline $\begin{array}{l}\mathrm{OKC} \\
\mathrm{AB}\end{array}$ & Syndecan-1 & $\begin{array}{l}26 \\
10\end{array}$ & $\begin{array}{l}39.58 \% \\
39.80 \%\end{array}$ & -0.245 & -0.012 & 0.8 \\
\hline $\begin{array}{l}\mathrm{OKC} \\
\mathrm{AB}\end{array}$ & $\mathrm{Ki}-67$ & $\begin{array}{l}26 \\
10\end{array}$ & $\begin{array}{l}23^{* *} \\
24^{* *}\end{array}$ & -0.2 & -1.05 & 0.8 \\
\hline
\end{tabular}

${ }^{*}$ Number of specimens. ${ }^{* *}$ Mean Ki-67 score.

In this study, the pattern of expression of maspin in $\mathrm{AB}$ was consistent with the findings of Kumamoto and Ooya [50], who reported stronger maspin reactivity in peripheral columnar or cuboidal cells than in central cells. Maspin expression has not been investigated in the OKC before. However, the abovementioned study compared maspin expression in tooth germs, ABs, and malignant ameloblastic tumors (metastasizing $\mathrm{ABs}$ and ameloblastic carcinomas) [50]. The expression was significantly higher in $A B s$ than in tooth germs, metastasizing $\mathrm{ABs}$ showed strong expression, while ameloblastic carcinomas showed weak expression in some cells. Similarly, maspin expression in this study was highest in $\mathrm{AB}$ compared to $\mathrm{DC}$ and $\mathrm{OKC}$, albeit statistically not significant. Therefore, it can be inferred that maspin expression increases from normal odontogenic structures to odontogenic cysts (DC and OKC), to the more locally aggressive tumor $(\mathrm{AB})$.

The regulation of expression of maspin, however, is a complex process, influenced by P53 and other members of the family, namely, P63 and P73 [51-53]. Studies have shown different patterns of expression of the P53 family proteins in the OKC compared to other odontogenic cysts $[8,12,14,15,17-25]$. This finding warrants additional research on maspin expression in the OKC concerning the P53 gene family members.
Syndecan-1 showed no significant differences between the three study groups, although the expression was lower in $\mathrm{AB}$ and OKC compared to DC. Syndecan-1 participates in cell proliferation, cell migration, intercellular adhesion, cell-matrix interactions, and cytoskeleton organization. Intercellular adhesion and attachment with the extracellular matrix are affected by the loss of its expression [44]. Downregulation of syndecan-1 expression has been reported in epithelial dysplasia and oral carcinoma $[44,54,55]$. It has been associated with poorer prognosis of oral carcinoma and increased aggressiveness of ameloblastoma [44, 47]. The lower syndecan-1 expression in the OKC compared with DC might explain its local aggressiveness and increased potential for recurrence in comparison with the clinical behavior of the DC. However, since the difference is not significant, it may be that its effect on aggressive behavior in the studied lesions is limited.

The results of this study are consistent with those of Nadalin et al., who found no significant difference in the expression of syndecan-1 between the DC and OKC [37]. They are also consistent with those of Etemad-Moghadam and Alaeddini [40], who compared syndecan-1 expression in different odontogenic lesions, including $\mathrm{AB}$ and $\mathrm{OKC}$. They found that only odontogenic myxomas showed a significant difference from other lesions since they showed no expression. 
The results are partially different from those of Al-Otaibi et al., and different from those of Al-Otaibi et al. [38, 41]. Brito-Mendoza et al. found no significant difference between $\mathrm{OKC}$ and $\mathrm{DC}$ but found the mean rank scores of $\mathrm{AB}$ to be significantly lower than those of OKC and DC [38]. The difference between this study and their study may be explained by the difference in the methodology used. While they applied semiquantitative analysis, we utilized a computerized image analysis system. It could also be explained by the variation in the degree of inflammation between lesions. Unlike this study, there is no mention in their research on the exclusion of markedly inflamed cases. It is worthwhile to mention here that Nadalin et al. observed low or absent expression of syndecan-1 in areas of OKC lining in which there was an alteration in epithelial morphology due to inflammation [37].

The distribution patterns of syndecan-1 in the epithelia of $\mathrm{DC}, \mathrm{OKC}$, and $\mathrm{AB}$ in this study were consistent with the findings of other studies [37, 38, 40,41]. They were, however, unlike those of Özcan et al., who reported a different distribution in the $\mathrm{OKC}$, describing it as a strong membranous expression in basal and suprabasal cells only, while, as in this study, it involved the full thickness of DC lining [39].

As for the Ki-67, positive nuclei were significantly higher in the OKC epithelial lining than that of the DC. The Ki-67 positive nuclei were predominantly in the suprabasal cell layer of the $\mathrm{OKC}$ with occasional ones in the basal cell layer, while they were mainly in the basal cell layer of the DC. The results of this study indicate that $\mathrm{OKC}$ has an intrinsic proliferative activity comparable to that of $\mathrm{AB}$ but significantly higher than that of DC. The findings of this study are consistent with those of other studies comparing the Ki-67 expression in the OKC to other odontogenic cysts. Those studies showed that the suprabasal cell layers in the epithelial lining of the OKC have higher proliferative activity when compared with the basal cell layer and when compared with the linings of other odontogenic cysts $[5,7,8,11-13,16-19]$. Some studies that compared the Ki-67 expression in the $\mathrm{OKC}$ with that in the $\mathrm{AB}$ reported a significantly higher proliferation index in the $\mathrm{OKC}$ than in $\mathrm{AB}[18,48,56,57]$, while one study reported the opposite, a significantly higher proliferation index in $\mathrm{AB}$ than in the OKC [58]. Similar to the results of this study, Thosaporn et al. reported a slightly higher but not significantly different proliferation index in $\mathrm{AB}$ than in OKC, using the IPO-38 antigen [59]. The difference from the studies which indicated a considerably higher proliferation index in the $\mathrm{OKC}$ than in $\mathrm{AB}$ might be explained by the strict criteria that were applied in selecting the specimens in this study. All sections showing considerable inflammation were excluded, ending up with only 47 specimens out of 200. Indeed, one study indicated a statistically significant increase in the expression of Ki-67 in the lining of inflamed OKCs compared to noninflamed ones [60]. Another study suggested that inflammation has no significant effect on the overall proliferation activity of OKC. However, a focal increase in Ki-67 expression adjacent to moderately to severely inflamed areas was found [61].

Since one of the main purposes of this study was to compare the $\mathrm{OKC}$ to a more aggressive odontogenic lesion, the conventional $\mathrm{AB}$ was chosen. Unicystic $\mathrm{AB}$ would not have served this purpose since the latter is known to have less aggressive clinical and biological behavior than conventional $\mathrm{AB}$ [62]. In this regard, it has been shown that the expression of syndecan-1 is higher in unicystic $\mathrm{AB}$ than in solid/ multicystic or conventional $\mathrm{AB}[38,47,63]$, and using it would affect the statistical significance of the results. However, it would be worthwhile in future studies to consider investigating additional biologic markers in different histologic variants of $A B$, including the unicystic.

\section{Conclusions}

The expressions of maspin and syndecan-1 do not powerfully represent differences in biologic behavior between $\mathrm{OKC}$, conventional AB, and DC. The expression of Ki-67, however, indicates comparable proliferative activities of $\mathrm{OKC}$ and conventional $\mathrm{AB}$, which are higher than that of DC.

Additional research on the biologic behavior of $\mathrm{OKC}$, considering more biologic markers and different control groups, is recommended to arrive at more specific conclusions regarding its classification.

\section{Data Availability}

The statistical data used to support the findings of this study are included within the article.

\section{Conflicts of Interest}

The authors declare that there are no conflicts of interest regarding the publication of this article.

\section{Acknowledgments}

This work was supported by the Jordan University of Science and Technology, Deanship of Research [grant no. 20110060].

\section{References}

[1] T.-J. Li, "The odontogenic keratocyst," Journal of Dental Research, vol. 90, no. 2, pp. 133-142, 2011.

[2] H. P. Philipsen, "Keratocystic odontogenic tumour," in World Health Organization Classification of Tumours. Pathology and Genetics of Head and Neck Tumours, L. Barnes, J. W. Eveson, P. Reichart, and D. Sidransky, Eds., pp. 306-307, IARC Press, Lyon, France, 2005.

[3] D. Bhargava, A. Deshpande, and M. A. Pogrel, "Keratocystic odontogenic tumour (KCOT)-a cyst to a tumour," Oral and Maxillofacial Surgery, vol. 16, no. 2, pp. 163-170, 2012.

[4] T. Takata and P. J. Slootweg, "Introduction to odontogenic and maxillofacial bone tumours," in WHO Classification of Head and Neck Tumours, A. K. El-Naggar, J. K. C. Chan, and J. R. Grandis, Eds., pp. 203-260, IARC, Lyon, France, 2017.

[5] J. B. Matthews, G. I. Mason, and R. M. Browne, "Epithelial cell markers and proliferating cells in odontogenic jaw cysts," The Journal of Pathology, vol. 156, no. 4, pp. 283-290, 1988.

[6] T.-J. Li, R. M. Browne, and J. B. Matthews, "Quantification of PCNA+ cells within odontogenic jaw cyst epithelium," Journal of Oral Pathology and Medicine, vol. 23, no. 4, pp. 184-189, 1994. 
[7] T.-J. Li, R. M. Browne, and J. B. Matthews, "Epithelial cell proliferation in odontogenic keratocysts: a comparative immunocytochemical study of Ki67 in simple, recurrent and basal cell naevus syndrome (BCNS)-associated lesions," Journal of Oral Pathology and Medicine, vol. 24, no. 5, pp. 221-226, 1995.

[8] P. J. Slootweg, "p53 protein and Ki-67 reactivity in epithelial odontogenic lesions. an immunohistochemical study," Journal of Oral Pathology and Medicine, vol. 24, no. 9, pp. 393397, 1995.

[9] A. Piattelli, M. Fioroni, A. Santinelli, and C. Rubini, "Expression of proliferating cell nuclear antigen in ameloblastomas and odontogenic cysts," Oral Oncology, vol. 34, no. 5, pp. 408-412, 1998.

[10] H. Takahashi, S. Fujita, S. Yamabe et al., "Comparison of proliferating cell nuclear antigen expression in odontogenic keratocyst and ameloblastoma: an immunohistochemical study," Analytical Cellular Pathology, vol. 16, no. 4, pp. 185-192, 1998.

[11] D. K. Kim, S. G. Ahn, J. Kim, and J. H. Yoon, "Comparative $\mathrm{Ki}-67$ expression and apoptosis in the odontogenic keratocyst associated with or without an impacted tooth in addition to unilocular and multilocular varieties," Yonsei Medical Journal, vol. 44, no. 5, pp. 841-846, 2003.

[12] E. Kichi, Y. Enokiya, T. Muramatsu et al., "Cell proliferation, apoptosis and apoptosis-related factors in odontogenic keratocysts and in dentigerous cysts," Journal of Oral Pathology and Medicine, vol. 34, no. 5, pp. 280-286, 2005.

[13] U. Saraçoğlu, B. Kurt, O. Günhan, and O. Güven, "MIB-1 expression in odontogenic epithelial rests, epithelium of healthy oral mucosa and epithelium of selected odontogenic cysts. an immunohistochemical study," International Journal of Oral and Maxillofacial Surgery, vol. 34, no. 4, pp. 432-435, 2005.

[14] M. G. de Oliveira, S. Lauxen Ida, A. C. Chaves, P. V. Rados, and M. Sant'Ana Filho, "Immunohistochemical analysis of the patterns of p53 and PCNA expression in odontogenic cystic lesions," Medicina Oral Patologia Oral Y Cirugia Bucal, vol. 13, no. 5, pp. E275-E280, 2008.

[15] C. A. S. Gurgel, E. A. G. Ramos, R. A. Azevedo, V. A. Sarmento, A. M. da Silva Carvalho, and J. N. dos Santos, "Expression of Ki-67, p53 and p63 proteins in keratocyst odontogenic tumours: an immunohistochemical study," Journal of Molecular Histology, vol. 39, no. 3, pp. 311-316, 2008.

[16] G. C. Mateus, G. H. Lanza, P. H. de Moura, H. A. Marigo, and M. C. Horta, "Cell proliferation and apoptosis in keratocystic odontogenic tumors," Medicina Oral, Patologia Oral Y Cirugia Bucal, vol. 13, no. 11, pp. E697-E702, 2008.

[17] A. Gadbail, M. Chaudhary, S. Patil, and M. Gawande, "Actual proliferating index and p53 protein expression as prognostic marker in odontogenic cysts," Oral Diseases, vol. 15, no. 7, pp. 490-498, 2009 Oct.

[18] J. de Vicente, A. Torre-Iturraspe, A. Gutiérrez, and P. Lequerica-Fernández, "Immunohistochemical comparative study of the odontogenic keratocysts and other odontogenic lesions," Medicina Oral Patología Oral Y Cirugia Bucal, vol. 15, no. 5, pp. e709-e715, 2010.

[19] M. G. de Oliveira, I. da Silva Lauxen, A. C. M. Chaves, P. V. Rados, and M. Sant'Ana Filho, "Odontogenic epithelium: immunolabeling of ki-67, EGFR and survivin in pericoronal follicles, dentigerous cysts and keratocystic odontogenic tumors," Head and Neck Pathology, vol. 5, no. 1, pp. 1-7, 2011.
[20] G. R. Ogden, D. M. Chisholm, R. A. Kiddie, and D. P. Lane, "p53 protein in odontogenic cysts: increased expression in some odontogenic keratocysts," Journal of Clinical Pathology, vol. 45, no. 11, pp. 1007-1010, 1992.

[21] T.-J. Li, R. M. Browne, S. S. Prime, I. C. Paterson, and J. B. Matthews, "p53 expression in odontogenic keratocyst epithelium," Journal of Oral Pathology and Medicine, vol. 25, no. 5, pp. 249-255, 1996 May.

[22] A. Piattelli, M. Fioroni, A. Santinelli, and C. Rubini, "P53 protein expression in odontogenic cysts," Journal of Endodontics, vol. 27, no. 7, pp. 459-461, 2001.

[23] L. Lo Muzio, A. Santarelli, R. Caltabiano et al., "p63 expression in odontogenic cysts," International Journal of Oral and Maxillofacial Surgery, vol. 34, no. 6, pp. 668-673, 2005.

[24] M. Mascitti, L. Togni, A. Balercia, P. Balercia, C. Rubini, and A. Santarelli, "p53-Family proteins in odontogenic cysts: an immunohistochemical study," Applied Immunohistochemistry \& Molecular Morphology, vol. 28, no. 5, pp. 369-375, 2018.

[25] M. A. Alsaegh, A. M. Altaie, and S. Zhu, "p63 expression and its relation to epithelial cells proliferation in dentigerous cyst, odontogenic keratocyst, and ameloblastoma," Pathology \& Oncology Research, vol. 26, no. 2, pp. 1175-1182, 2019.

[26] S. Levanat, R. J. Gorlin, S. Fallet, D. R. Johnson, J. E. Fantasia, and A. E. Bale, "A two-hit model for developmental defects in Gorlin syndrome," Nature Genetics, vol. 12, no. 1, pp. 85-87, 1996.

[27] N. J. Lench, A. S. High, A. F. Markham, W. J. Hume, and P. A. Robinson, "Investigation of chromosome 9q22.3-q31 DNA marker loss in odontogenic keratocysts," European Journal of Cancer Part B: Oral Oncology, vol. 32, no. 3, pp. 202-206, 1996.

[28] N. J. Lench, E. A. Telford, A. S. High, A. F. Markham, C. Wicking, and B. J. Wainwright, "Characterisation of human patched germ line mutations in naevoid basal cell carcinoma syndrome," Human Genetics, vol. 100, no. 5-6, pp. 497-502, 1997.

[29] D. C. Barreto, R. S. Gomez, A. E. Bale, W. L. Boson, and L. De Marco, "PTCH gene mutations in odontogenic keratocysts," Journal of Dental Research, vol. 79, no. 6, pp. 1418-1422, 2000.

[30] N. P. Agaram, B. M. Collins, L. Barnes et al., "Molecular analysis to demonstrate that odontogenic keratocysts are neoplastic," Archives of Pathology \& Laboratory Medicine, vol. 128, no. 3, pp. 313-317, 2004.

[31] K. Ohki, H. Kumamoto, R. Ichinohasama, T. Sato, N. Takahashi, and K. Ooya, "PTC gene mutations and expression of SHH, PTC, SMO, and GLI-1 in odontogenic keratocysts," International Journal of Oral and Maxillofacial Surgery, vol. 33, no. 6, pp. 584-592, 2004.

[32] M. Grachtchouk, J. Liu, A. Wang et al., "Odontogenic keratocysts arise from quiescent epithelial rests and are associated with deregulated hedgehog signaling in mice and humans," The American Journal of Pathology, vol. 169, no. 3, pp. 806814, 2006.

[33] X. Wang, Y. Lu, G. Shen, and W. Chen, "One germline mutation of PTCH gene in a Chinese family with non-syndromic keratocystic odontogenic tumours," International Journal of Oral and Maxillofacial Surgery, vol. 40, no. 8, pp. 829-833, 2011.

[34] M. A. Pogrel and R. C.K. Jordan, "Marsupialization as a definitive treatment for the odontogenic keratocyst," Journal of Oral and Maxillofacial Surgery, vol. 62, no. 6, pp. 651-656, 2004. 
[35] J. M. Wright and M. Vered, "Update from the 4th edition of the world health organization classification of head and neck tumours: odontogenic and maxillofacial bone tumors," Head and Neck Pathology, vol. 11, no. 1, pp. 68-77, 2017.

[36] P. M. Speight and T. Takata, "New tumour entities in the 4th edition of the world health organization classification of head and neck tumours: odontogenic and maxillofacial bone tumours," Virchows Archiv, vol. 472, no. 3, pp. 331-339, 2018.

[37] M. R. Nadalin, E. R. Fregnani, Y. T. C. Silva-Sousa, and D. E. d. C. Perez, "Syndecan-1 (CD138) and Ki-67 expression in odontogenic cystic lesions," Brazilian Dental Journal, vol. 22, no. 3, pp. 223-229, 2011.

[38] O. Al-Otaibi, R. Khounganian, S. Anil, and R. Rajendran, "Syndecan-1 (CD 138) surface expression marks cell type and differentiation in ameloblastoma, keratocystic odontogenic tumor, and dentigerous cyst," Journal of Oral Pathology \& Medicine, vol. 42, no. 2, pp. 186-193, 2013.

[39] A. Özcan, I Yavan, and Ö Günhan, "Immunohistochemical characteristics of cystic odontogenic lesions: a comparative study," Turkish Journal of Pathology, vol. 31, no. 2, pp. 104-110, 2015.

[40] S. Etemad-Moghadam and M. Alaeddini, "A comparative study of syndecan-1 expression in different odontogenic tumors," Journal of Oral Biology and Craniofacial Research, vol. 7, no. 1, pp. 23-26, 2017.

[41] L. Brito-Mendoza, R. Bologna-Molina, M. E. Irigoyen-Camacho, G. Martinez, C. Sánchez-Romero, and A. MosquedaTaylor, "A comparison of Ki67, syndecan-1 (CD138), and molecular RANK, RANKL, and OPG triad expression in odontogenic keratocyts, unicystic ameloblastoma, and dentigerous cysts," Disease Markers, vol. 2018, pp. 1-7, 2018.

[42] Z. Z. Khalkhali-Ellis, "Maspin: the new frontier," Clinical Cancer Research, vol. 12, no. 24, pp. 7279-7283, 2006.

[43] U. H. Weidle, F. Birzele, and G. Tiefenthaler, "Potential of protein-based anti-metastatic therapy with serpins and inter $\alpha$-trypsin inhibitors," Cancer Genomics - Proteomics, vol. 15, no. 4, pp. 225-238, 2018.

[44] M. Máthé, Z. Suba, Z. Németh et al., "Stromal syndecan-1 expression is an adverse prognostic factor in oral carcinomas," Oral Oncology, vol. 42, no. 5, pp. 493-500, 2006.

[45] M. Palaiologou, I. Delladetsima, and D. Tiniakos, "CD138 (syndecan-1) expression in health and disease," Histology and Histopathology, vol. 29, no. 2, pp. 177-189, 2014.

[46] R. A. Safadi, A. S. Musleh, T. H. Al-Khateeb, and A. A.-H. Hamasha, "Analysis of immunohistochemical expression of $\mathrm{k} 19$ in oral epithelial dysplasia and oral squamous cell carcinoma using color deconvolution-image analysis method," Head and Neck Pathology, vol. 4, no. 4, pp. 282-289, 2010.

[47] R. Bologna-Molina, A. Mosqueda-Taylor, E. Lopez-Corella et al., "Syndecan-1 (CD138) and Ki-67 expression in different subtypes of ameloblastomas," Oral Oncology, vol. 44, no. 8, pp. 805-811, 2008.

[48] M. S. Tekkesin, S. Mutlu, and V. Olgaç, "Expressions of bax, bcl-2 and Ki-67 in odontogenic keratocysts (keratocystic odontogenic tumor) in comparison with ameloblastomas and radicular cysts," Turkish Journal of Pathology, vol. 28, no. 1, pp. 49-55, 2012.

[49] M. Vered, I. Allon, A. Buchner, and D. Dayan, "Is maspin immunolocalization a tool to differentiate central low-grade mucoepidermoid carcinoma from glandular odontogenic cyst?," Acta Histochemica, vol. 112, no. 2, pp. 161-168, 2010.

[50] H. Kumamoto and K. Ooya, "Immunohistochemical detection of uPA, uPAR, PAI-1, and maspin in ameloblastic tumors," Journal of Oral Pathology \& Medicine, vol. 36, no. 8, pp. 488-494, 2007.

[51] Z. Zou, C. Gao, A. K. Nagaich et al., "p53 regulates the expression of the tumor suppressor gene maspin," Journal of Biological Chemistry, vol. 275, no. 9, pp. 6051-6054, 2000.

[52] K. Spiesbach, A. Tannapfel, J. Mössner, and K. Engeland, "TAp63 $\gamma$ can substitute for p53 in inducing expression of themaspintumor suppressor," International Journal of Cancer, vol. 114, no. 4, pp. 555-562, 2005.

[53] K. E. King, D. M. Reddi, R. M. Ponnamperuma, M. Gerdes, and W. C. Weinberg, "Dysregulated $\Delta \mathrm{Np} 63 \alpha$ negatively regulates the maspin promoter in keratinocytes via blocking endogenous p73 binding," Molecular Carcinogenesis, vol. 53, no. 9, pp. 698-710, 2014.

[54] H. Kurokawa, S. Matsumoto, T. Murata et al., "Immunohistochemical study of syndecan-1 down-regulation and the expression of $\mathrm{p} 53$ protein or Ki-67 antigen in oral leukoplakia with or without epithelial dysplasia," Journal of Oral Pathology and Medicine, vol. 32, no. 9, pp. 513-521, 2003.

[55] T. Muramatsu, "Reduced expression of syndecan-1 in oral cancer," Oral Cancer, 2012.

[56] F. R. Amaral, G. C. P. Mateus, L. A. Bonisson et al., "Cell proliferation and apoptosis in ameloblastomas and keratocystic odontogenic tumors," Brazilian Dental Journal, vol. 23, no. 2, pp. 91-96, 2012.

[57] R. Metgud and K. Gupta, "Expression of cell cycle and apoptosis-related proteins in ameloblastoma and keratocystic odontogenic tumor," Annals of Diagnostic Pathology, vol. 17, no. 6, pp. 518-521, 2013.

[58] A. R. Gadbail, R. Patil, and M. Chaudhary, "Co-expression of $\mathrm{Ki}-67$ and p53 protein in ameloblastoma and keratocystic odontogenic tumor," Acta Odontologica Scandinavica, vol. 70, no. 6, pp. 529-535, 2012.

[59] W. Thosaporn, A. Iamaroon, S. Pongsiriwet, and K. Ng, "A comparative study of epithelial cell proliferation between the odontogenic keratocyst, orthokeratinized odontogenic cyst, dentigerous cyst, and ameloblastoma," Oral Diseases, vol. 10, no. 1, pp. 22-26, 2004.

[60] A. M. B. Paula, J. N. Carvalhais, M. G. Domingues, D. C. Barreto, and R. A. Mesquita, "Cell proliferation markers in the odontogenic keratocyst: effect of inflammation," Journal of Oral Pathology and Medicine, vol. 29, no. 10, pp. 477-482, 2000.

[61] I. Kaplan and A. Hirshberg, "The correlation between epithelial cell proliferation and inflammation in odontogenic keratocyst," Oral Oncology, vol. 40, no. 10, pp. 985-991, 2004.

[62] Z. S. Peacock, "Adjunctive strategies for benign maxillofacial Pathology," Oral and Maxillofacial Surgery Clinics of North America, vol. 31, no. 4, pp. 569-578, 2019.

[63] R. G. Carreón-Burciaga, R. González-González, N. MolinaFrechero, S. López-Verdín, V. Pereira-Prado, and R. BolognaMolina, "Differences in E-cadherin and syndecan-1 expression in different types of ameloblastomas," Analytical Cellular Pathology, vol. 2018, pp. 1-10, 2018. 